\title{
Research of Electrical Conductivity Measurement System for Mine Bursting Water Based on Dual Frequency Method
}

\author{
Zhou Mengran, He Chenyang, Liu Dong, Wu Xiaoyun \\ Department of Electric Engineering, Anhui University of Science and Technology, Huainan, China
}

\begin{abstract}
This paper presents a double frequency conductivity measurement method for measuring mine bursting water, to solve the capacitance effect of the conductivity sensor itself has the help. The core controller of the system is the single chip microcomputer ATMEGA128. This paper introduces the basic principle of the measurement of the existing problems and the dual frequency measurement method, and then introduces and analyzes the hardware. To test and analyze the collected data, the double frequency method is found to have good stability and accuracy in the measurement of the electrical conductivity of mine inrush water. It is proved that the method and the system design of the hardware circuit can accurately measure the electric conductivity of the mine inrush water source.
\end{abstract}

\section{Introduction}

Mine flood is one of the major hazards in coal mine production safety, mine water inrush occurred suddenly, flooding tunnels quickly, causing economic dangerous, and can causing casualties, it is possible to real-time recognition of mine water inrush sources, grasp the characteristics of underground water, the safety in production of mine has important significance. This design through the measurement of underground water conductivity to determine mine bursting water type and real-time control of water source changes, in order to solve the conductivity cell capacitance can not be measured. In this paper, by using dual frequency determination method to determine the sensor resistance capacitance network charge and discharge time constant, so as to effectively eliminate the influence of distributed capacitance, improving the measurement accuracy of the system greatly [1]-[4].

\section{Principle of Measurement}

Conductivity sensor measuring principle is to add certain voltage of two parallel plate electrodes into the solution to be measured in, in order to prevent the electrode polarization, usually has a high frequency $\mathrm{AC}$ voltage, through the current flowing between the measuring electrode to obtain conductivity. According to Ohm's law, the conductance of the conductor $\mathrm{G}$ is the reciprocal of the resistance $R$, and the resistance of the solution is directly proportional to the distance between the electrode and the L, and is inversely proportional to the cross-sectional area of the electrode A [5]-[7]. As the follow:

$$
R=\rho(L / A)
$$

In the follow, $\rho$ is resistivity have $1 \mathrm{~cm}$ long, resistance conductor cross-sectional area of $1 \mathrm{C}$, the value of which is decided by the nature of the material itself.

The electrical conductivity can be expressed as the next follow:

$$
G=1 / R=(1 / \rho) \times(A / L)=K \times(1 / J)
$$

In the follow, $\mathrm{K}$ is the electrical conductivity, $\mathrm{J}$ is the electrode constant. From the above analysis, we can know that the resistance value of the solution can be obtained.

In the actual measurement, the conductivity sensor and measured the composition of the solution conductivity cell is a complex electrochemical system, there is $C_{m}$ inter electrode capacitance between two electrodes, between the capacitor and resistor $R_{m}$ in series, also lead electrodes exist lead capacitance $C_{n}$, between the capacitor and the resistance and capacitance composed of series parallel circuit ${ }^{[8-11]}$. Under normal circumstances, the value of lead capacitor is $\mathrm{pF}$ level, and capacitance between electrodes is $\mu \mathrm{F}$ level. $C_{m}>>C_{n}$. When two ends of the electrode add high-frequency alternating current, the capacitance $C_{m}$ is very small, can be neglected [12], [13].

The source of mine bursting water is a solution of low resistance, so available high frequency $\mathrm{AC}$ signal as excitation source, the measurement system choice 
$0 \sim 5000 \mathrm{~Hz}$ square wave signal, neglecting the influence of capacitance between the electrodes, conductance pool available Fig. 2 shows the equivalent circuit.

In the Fig. 3, $\mathrm{R}$ is the range switching resistance, $\mathrm{U}$ is the sensor output voltage, this voltage is amplified by the signal amplification circuit into the precision half wave rectifier circuit to filter negative voltage, and then for the microcontroller ADC sampling. Therefore, it can get the final signal sampled for DC output by half wave rectification.

Under the action of the sinusoidal signal with frequency $\omega$, the RC parallel impedance is

$$
Z=\frac{R(1-j w R C)}{1+w^{2} R^{2} C^{2}}
$$

Mode of impedance is

$$
|Z|=\frac{R}{\sqrt{1+w^{2} R^{2} C^{2}}}
$$

Phase angle is

$$
\varphi=-\operatorname{arctg}(w R C)
$$

In parallel model of $\mathrm{RC}$, when $\omega \mathrm{RC}<<1, \mathrm{Z}$ is similar to $\mathrm{R}$. Conductivity meter is mostly used the $\mathrm{AC}$ conductance determination method, because of not considering the factors that the phase angle between the voltage and the current, so the measured resistance is used to replace the $Z$. However, due to the influence of the capacitor R, C is very large, it is clear that the measurement will bring a large error.

The effective value and peak value of the input and output sine wave are measured under the action of the sine signal, and the numerical value obtained by the formula calculation is the reciprocal of the impedance modulus $1 / Z$. When the frequency of the sinusoidal signal is $2 \omega$, the mode of RC is

$$
|Z|=\frac{R}{\sqrt{1+4 w^{2} R^{2} C^{2}}}
$$

When $t=w^{2} R^{2} C^{2}, r=|Z| /|Z|^{\prime}$, have follows

$$
r=\sqrt{\frac{1+4 t}{1+t}} \text { or } t=\frac{r^{2}-1}{4-r^{2}}
$$

And have a follow

$$
R=|Z| \cdot \sqrt{1+t}
$$

To solve the actual water resistance $R$, there is no theory error, the complete elimination of the influence of AC conductance measurement method of capacitance effect on the precision of measurement, finally get water conductivity, the realization of the determination of conductivity of dual frequency. The equivalent circuit of the conductivity cell is shown in Fig. 1. It can be simplified equivalent circuits are obtained, as shown in Fig. 2.

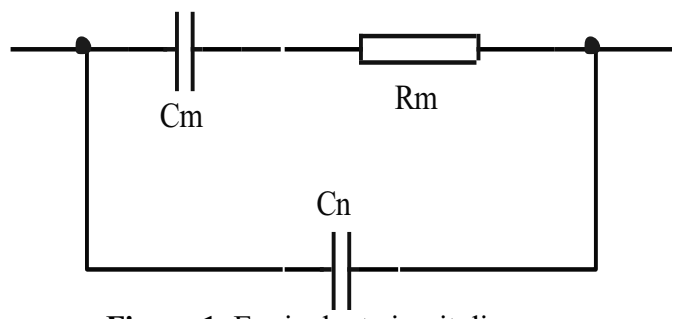

Figure 1. Equivalent circuit diagram.

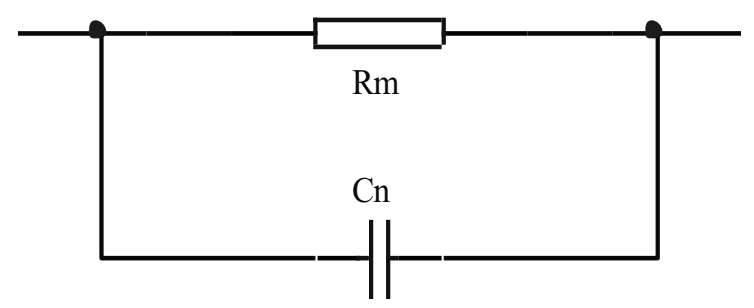

Figure 2. Simplified equivalent circuit diagram.

Thus dual frequency measurement principle diagram as shown in Fig. 3.

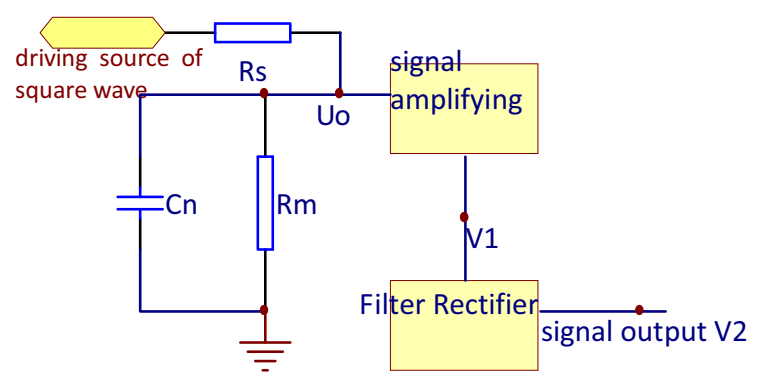

Figure 3. Principle diagram of dual frequency measurement.

\section{Test Result Process \& Analysis}

The 5 water samples extracted from a mining area in Huainan were used as the system to test the water samples. The water samples were collected from 111302 goaf water, 111305 goaf water, 1 layer of sandstone water, 9 layer of sandstone water and ordovician limestone water.

Make 5 times to measure 5 kinds of water were recorded as D1-D5, then use the frequency determination model for the system of sampling data measuring and processing, also for the 5 measurements were recorded as S1-S5. In the end, the two sets of data are compared with the original value of water samples, as shown in Fig. 4.

From Fig. 4, after the measurement group is more obvious than dual frequency measurement model after measuring group of ordinary algorithm more accurate. Compared with the original electrical conductivity, the measurement results of D group were obviously not close to the original conductivity of the $\mathrm{S}$ group.

The measurement results of $\mathrm{D}$ group and $\mathrm{S}$ group were screened respectively, and a group of results that can represent the characteristics of each group were selected. The results and the original values are statistics in Table 1. 
Table 1. Measurement result

\begin{tabular}{|c|c|c|c|c|c|}
\hline & $\begin{array}{c}111302 \\
\text { goaf } \\
\text { water }\end{array}$ & $\begin{array}{c}111305 \\
\text { goaf } \\
\text { water }\end{array}$ & $\begin{array}{c}\text { 1 layer of } \\
\text { sandstone } \\
\text { water }\end{array}$ & $\begin{array}{c}\text { 9 layer of } \\
\text { sandstone } \\
\text { water }\end{array}$ & $\begin{array}{c}\text { ordovician } \\
\text { limestone } \\
\text { water }\end{array}$ \\
\hline D & 1974.33 & 3626.13 & 5319.51 & 7012.84 & 4113.47 \\
\hline S & 2201.04 & 3986.29 & 5894.96 & 7286.17 & 4352.28 \\
\hline O & 2157.55 & 4024.53 & 5940.69 & 7338.52 & 4372.28 \\
\hline
\end{tabular}

From Table 1 data shows, without taking into account the conductivity cell is the influence of distributed capacitance, the measured results and the real value has always been rather too small. Because existence of capacitor lead to the conductivity cell voltage across a resistor is rising less than the steady-state value of sake. Taking into account the effect of capacitance, the use of dual frequency measurement method can be clearly seen that the compensation effect, although there are errors, but the range is within \pm 70 , require the measurement accuracy.

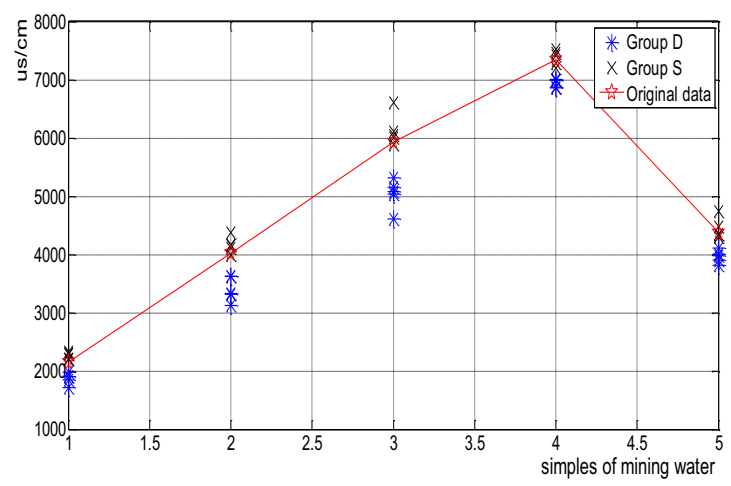

Figure 4. Data comparison.

\section{Summary}

System has been high-speed ATmega128 microcontroller to build hardware platform, combined with dual frequency determination of influence of distributed capacitance compensation method of sensor, not only improve the measurement accuracy in the system, and improve the system of data processing is fast, the system of mine water inrush early-warning ability can be improved.

\section{Acknowledgements}

Supportive fund, Project number. For example, 12th Five-Year key Project supported by the National Science and Technology(Grant No. 2013BAK06B01).

\section{References}

1. Liu Y J, Hao Q, Smalley J S T, et al. A frequency-addressed plasmonic switch based on dual-frequency liquid crystals[J]. Applied Physics Letters, 2010, 97(9):091101-091101-3.

2. Cai W, Liu B, Duan S, et al. An Islanding Detection Method based on Dual-Frequency Harmonic Current Injection under Grid Impedance Unbalanced Condition $[\mathrm{J}]$. IEEE Transactions on Industrial Informatics, 2013, 9(2):1178-1187.

3. Trokhanova O V, Okhapkin M B, Korjenevsky A V. Dual-frequency electrical impedance mammography for the diagnosis of non-malignant breast disease. [J]. Physiological Measurement, 2008, 29(6):S331-S344.

4. $\mathrm{Hu} \mathrm{S}, \mathrm{Wu} \mathrm{K}$, Wang $\mathrm{H}$, et al. Electrical conductivity measurement method in seawater desalination based on variable frequency excitation $[\mathrm{C}] / /$ Electronic Measurement \& Instruments, 2009. ICEMI '09. 9th International Conference on. IEEE, 2009:1-810 1-813.

5. Ji H, Chang Y, Huang Z, et al. Voidage measurement of gas-liquid two-phase flow based on Capacitively Coupled Contactless Conductivity Detection[J]. Flow Measurement \& Instrumentation, 2014, 40.

6. Cai-Ping L I, Zhang Y M, Zhang Z G. Design of monitoring and control system for water bursting in floor of coal seam $[\mathrm{J}]$. Industry \& Mine Automation, 2013.

7. Yan D, Xi Y, Pan L. Coal Floor Water Bursting Risk Evaluation System Based on Water Bursting Coefficient_-A Case Study in Gujiao Mine Area, Xishan Coalfield, Taiyuan, Shanxi[J]. Coal Geology of China, 2010.

8. Guo M, Chen X, Liu W, et al. Application of technology combined GIS and transient electromagnetic technique in coal mine water burst prevention - A case of Sihe Coal mine[C]// International Conference on Geoinformatics. IEEE, 2011:1-5.

9. Wang J, Li X, Cui T, et al. Application of distance discriminant analysis method to headstream recognition of water-bursting source[J]. Procedia Engineering, 2011, 26(4):374-381.

10. Wei-Wei H U, Zhi-Yuan M A, Cao H D, et al. Application of Isotope and Hydrogeochemical Methods in Distinguishing Mine Bursting Water Source[J]. Journal of Earth Sciences \& Environment, 2010.

11. Wu L. An Analysis and Countermeasure under Water Bursting of Xialei Branch Mine of Daxin Manganese Mine under Water Bursting $[\mathrm{J}]$. Chinas Manganese Industry, 2010. 
12. Wu Q, Yang L, Zhu B, et al. Application of Vulnerability Index Method in Coal Floor Water Bursting Evaluation in Zhaogezhuang Coalmine[J]. Coal Geology of China, 2009.
13. Hongqing Y U, Xing W. Reasons Analysis and Prevention Measures of Water Bursting From Hidden Subsided Column in Huangcun Branch Coal Mine 10111 Working Face[J]. Safety in Coal Mines, 2014. 